\title{
Electrochemical Detection of Dopamine in Presence of Serotonin and Ascorbic acid at Tetraoctyl ammonium bromide Modified Carbon Paste Electrode: A Voltammetric Study
}

\author{
Shankar SS ${ }^{1,3}$, Shereema RM ${ }^{1,4}$, Prabhu GRD², TP Rao ${ }^{1,4}$ and Kumara Swamy BE ${ }^{3 *}$ \\ ${ }^{1}$ Chemical Sciences and Technology Division (CSTD), Trivandrum, India \\ ${ }^{2}$ Agroprocessing and Natural Products Division (ANPD), CSIR-National Institute for Interdisciplinary Science and Technology (CSIR-NIIST), Trivandrum, India \\ ${ }^{3}$ Department of P.G. Studies and Research in Industrial Chemistry, Kuvempu University, Jnana Sahyadri, Shankaraghatta, Karnataka, India \\ ${ }^{4}$ Academy of Scientific and Innovative Research (AcSIR), New Delhi, India
}

\begin{abstract}
An electrochemical simultaneous evaluation of dopamine (DA), serotonin (5-HT) and ascorbic acid (AA) in phosphate buffer solution (PBS) of $\mathrm{pH} 7.4$ was attempted using a cationic surfactant, tetraoctylammonium bromide, modified carbon paste electrode (TOABMCPE). At the modified electrode, a well-defined redox peak with a great enhancement in current was witnessed. The oxidation of DA was found to be greatly $\mathrm{pH}$ dependent. The TOAB fabricated electrode overcomes the problem of resolution of DA with the coexisting species, AA and 5-HT. Simultaneous studies through cyclic voltammetric and differential voltammetric techniques gave excellent results with a great potential difference between DA-AA and DA-5-HT. The detection limit of the modified electrode was found to be $0.019 \mu \mathrm{M}$ with the aid of amperometry. The developed sensor was applied for the detection of DA in injection samples.
\end{abstract}

Keywords: Surfactants; Modified electrode; Dopamine; Biosensor; Simultaneous

\section{Introduction}

The challenge of determination of dopamine (DA) and serotonin (5-HT) concentration in the presence of ascorbic acid (AA) has triggered the development of voltammetric sensors in the recent past. DA, chemically known as 4-(2-aminoethyl) benzene-1, 2-diol, widely distributed in the mammalian brain tissues, is one of the crucial catecholamine neurotransmitters [1] which plays a pivotal role in the function of the cardiovascular, hormonal, renal and central nervous systems [2-5]. Abnormal levels of DA are linked with various disorders including, Parkinson's disease, Tourette's syndrome, Schizophrenia, attention deficit hyperactive disorder and generation of pituitary tumors [6-8]. Since the determination of DA in biological systems is informative in the diagnosis of aforementioned diseases, it is currently the subject of interest in biologically oriented research. Likewise, Serotonin (5-hydroxytryptamine or 5-HT), a monoamine neurotransmitter which is also extensively distributed in the brain, correspondingly plays significant roles in various pharmacological, physical and biological processes including temperature regulation, muscle contraction, liver regeneration, endocrine regulation and depression [9-13]. Copious studies revealed the influence that DA and 5-HT have on each other in their respective releasing. Consequently, simultaneous measurement of DA and 5-HT is a necessity, while they coexist in a biological system [14]. Conversely, a major obstacle encountered in the simultaneous determination of DA and 5-HT is the co-existence of high concentration of AA in vivo, of which the oxidation potential is adjacent to that of DA and 5-HT at the bare electrode, resulting in an overlapping voltammetric response. A great deal of effort has been directed towards the separation of anodic peaks of DA, 5-HT and AA with the assistance of several chemically modified electrodes [15-18]. Parallel determination of several neurotransmitters through $\mathrm{CV}$, however, remains a challenge. The strategy now is to design electrodes that can allow simultaneous detection of plentiful neurotransmitters, while eliminating the interfering effects of AA.

Surfactants, a class of amphiphilic molecules with a hydrophilic head on one side and a long hydrophobic tail on the other, have marked extensive applications in the field of electroanalytical chemistry $[19,20]$ and electrochemistry $[21,22]$ because of the enhancement effect and its ability to improve the property of the electrode-solution interface. The usage of surfactants as modifiers to improve the electrode quality has been reported previously [19,23-26]. This electrode exhibited strong cation exchange property and improved electron transfer rate between the substrates and the electrode. Surfactants have also been in use for the immobilization of biomolecules on electrodes. Their applications are also extended successfully in the study of proteins. The electron transfer from electrode to redox proteins including, myoglobin, hemoglobin, was found to be facilitated in the surfactant films [27-30]. The modified carbon working electrode with Cationic surfactants including (CTAB) has proved significant improvement in the electrochemical response of various species [31]. Tetraoctylammonium bromide (TOAB), a quaternary ammonium compound with the chemical formula, $\left[\mathrm{CH}_{3}\left(\mathrm{CH}_{2}\right)_{7}\right] 4 \mathrm{~N} \mathrm{Br}$, finds its general application as a phase transfer catalyst between an aqueous and an organic solution.

The development of a sensitive electrochemical method for the simultaneous determination of DA, AA and 5-HT through a modified BCPE with a cationic surfactant (TOAB) was the core objective of this work. The electrochemical behavior of DA, AA and 5-HT were

*Corresponding author: Kumara Swamy BE, Department of P.G. Studies and Research in Industrial Chemistry, Kuvempu University, Jnana Sahyadri, Shankaraghatta, Karnataka, India, 577 451, Tel: +91-8282-256225; E-mail: kumaraswamy21@yahoo.com

Received May 01, 2015; Accepted June 10, 2015; Published June 20, 2015

Citation: Shankar SS, Shereema RM, Prabhu GRD, Rao TP, Kumara Swamy BE (2015) Electrochemical Detection of Dopamine in Presence of Serotonin and Ascorbic acid at Tetraoctyl ammonium bromide Modified Carbon Paste Electrode: A Voltammetric Study. J Biosens Bioelectron 6: 168. doi:10.4172/21556210.1000168

Copyright: (c) 2015 Shankar SS, et al. This is an open-access article distributed under the terms of the Creative Commons Attribution License, which permits unrestricted use, distribution, and reproduction in any medium, provided the original author and source are credited. 
Citation: Shankar SS, Shereema RM, Prabhu GRD, Rao TP, Kumara Swamy BE (2015) Electrochemical Detection of Dopamine in Presence of Serotonin and Ascorbic acid at Tetraoctyl ammonium bromide Modified Carbon Paste Electrode: A Voltammetric Study. J Biosens Bioelectron 6: 168. doi:10.4172/2155-6210.1000168

Page 2 of 7

investigated. A great escalation in the oxidation peak currents of DA, AA and 5-HT was observed at the TOABMCPE, compared with those at BCPE. With this background, a novel, sensitive and convenient electrochemical method was developed for the individual and simultaneous determination of these compounds, which could find its successful application in the determination of dopamine in dopamine hydrochloride injection.

\section{Experimental Section}

\section{Chemical reagents}

DA stock solution was prepared in $0.1 \mathrm{M}$ perchloric acid; whereas $0.1 \mathrm{mM}$ TOAB, $0.1 \mathrm{mM} \mathrm{5-HT}$ and $1 \mathrm{mM}$ AA in double distilled water. Aforementioned chemicals were of analytical grade and were used without any further purification. DA was purchased from Sterile Specialities India Pvt Ltd and Ajantha Pharma (Enikepadu, Vijayawada). Standard method was employed in the preparation of Phosphate buffer solution (PBS). The water used was double distilled. All the experiments were performed at room temperature.

\section{Apparatus and procedure}

A VSP-potentiostat/galvanostat (Biologic Science Instruments) was utilized to conduct the experiments. All the experiments bore a conventional three-electrode system which consisted of a working carbon paste electrode with homemade cavity of $3 \mathrm{~mm}$ diameter, a platinum wire as counter electrode and a saturated calomel electrode as reference electrode. $70 \%$ graphite powder and $30 \%$ silicon oil was manually ground in an agitate mortar for about 30 minute to get a homogenous mixture for the preparation of a bare carbon paste electrode. The paste was packed into the cavity CPE and smoothened on weighing paper. $30 \mu \mathrm{L}$ TOAB was immobilized on the surface of carbon paste electrode for $15 \mathrm{~min}$ to prepare the modified electrode. After this, the fabricated TOAB modified CPE was washed with water and data were recorded in $\mathrm{pH}$ 7.4 PBS.

\section{Results and Discussion}

\section{Surface morphology of the TOABMCPE}

Scanning electron microscopy is apt to exemplify the electrode surface morphology. Figure S1 showed the surface morphology of TOABMCPE. Isolated and irregularly shaped graphite flakes of BCPE surface had completely transformed into smooth and regularly arranged particles throughout the surface of TOABMCPE. The significant differences in the surface morphology of both electrodes suggest that the TAOB were entrenched onto the surface of BCPE.

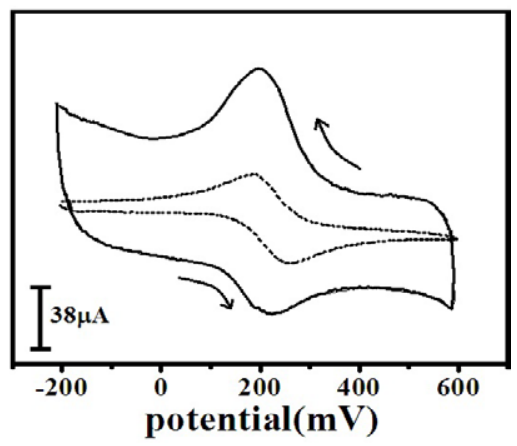

Figure 1: Cyclic voltammogram of $1 \mathrm{~m} \mathrm{M}$ potassium ferrocyanide in 1 $\mathrm{M} \mathrm{KCl}$ at BCPE (dotted line) and TAOBMCPE (solid line). Scan rate $50 \mathrm{mV} / \mathrm{s}$.

\section{Electrochemical behavior of potassium ferrocyanide at TOABMCPE}

Figure 1 showed the cyclic voltammograms of $1 \mathrm{mM} \mathrm{K}_{4} \mathrm{Fe}(\mathrm{CN})_{6}$ in $1 \mathrm{M} \mathrm{KCl}$ as supporting electrolyte at TOABMCPE. At TOABMCPE, the background current was greatly enlarged compared with that at bare $\mathrm{CPE}$. This indicates the significant change in surface property of the modified electrode. In contrast to the poor response at bare CPE (dotted line), the electrochemical signal of $\mathrm{K}_{4} \mathrm{Fe}(\mathrm{CN})_{6}$ showed an enhancement at TOABMCPE (solid line), which is reflected in the improvement of both the shape of redox peaks and the magnification of peak currents. The oxidation and reduction peaks were located at $242 \mathrm{mV}$ and 194 $\mathrm{mV}$ respectively at the bare CPE. Whereas, at the TOABMCPE, in the potential range of -200 to $600 \mathrm{mV}$, a pair of well-defined redox peaks appeared at $234 \mathrm{mV}$ and $175 \mathrm{mV}$ with $\Delta \mathrm{Ep}=59 \mathrm{mV}$. These outcomes reveal the excellent catalytic activity of TOABMCPE towards the electro active species.

The TOABMCPE provides more surface area than the unmodified carbon paste electrode. Cyclic voltammety of $1 \mathrm{mM} \mathrm{K}_{4} \mathrm{Fe}(\mathrm{CN})_{6}$ in $0.1 \mathrm{M}$ $\mathrm{KCl}$ solution at various scan rates gave information about the surface area. From Randles-Sevcik equation,

$$
\mathrm{Ip}=2.69 \times 10^{5} \mathrm{n}^{3 / 2} \mathrm{AC}_{\mathrm{o}} \mathrm{D}_{\mathrm{R}}{ }^{1 / 2} v^{1 / 2}
$$

where $I_{p}$ is the peak current, $n$ is the number of electrons transferred, $A$ is the surface area of the electrode $\left(\mathrm{cm}^{2}\right)$, DR is the diffusion coefficient of the molecule in solution $\left(\mathrm{cm}^{2} / \mathrm{s}\right), v$ is the scan rate $(\mathrm{V} / \mathrm{s})$ and $\mathrm{Co}$ corresponds to the bulk concentration of the probe $\left(\mathrm{mol} / \mathrm{cm}^{3}\right)$. The surface area could be calculated from the slope of the plot of $I_{p} V_{s} v^{1 / 2}$ $\left(1 \mathrm{mM} \mathrm{K}_{4} \mathrm{Fe}(\mathrm{CN})_{6}, \mathrm{n}=1, \mathrm{DR}=7.6 \times 10^{-6} \mathrm{~cm} \mathrm{~s}^{-1}\right)$ and was found to be $0.0024 \mathrm{~cm}^{2}$ for BCPE and $0.0048 \mathrm{~cm}^{2}$ for TOABMCPE.

\section{Optimization of concentration and immobilization time of TOAB}

The electrochemical response of $\mathrm{K}_{4} \mathrm{Fe}(\mathrm{CN})_{6}$ at the $\mathrm{BCPE}$ and TOABMCPE clearly illustrates that the TOABMCPE can remarkably improve the redox peak current of $\mathrm{K}_{4} \mathrm{Fe}(\mathrm{CN})_{6}$. However, further studies showed that the amount of TOAB in modified carbon paste electrode also affects the electrochemical response of $\mathrm{K}_{4} \mathrm{Fe}(\mathrm{CN})_{6}$. The influence of $\mathrm{TOAB}$ concentration towards the oxidation peak current of $\mathrm{K}_{4} \mathrm{Fe}(\mathrm{CN})_{6}$ Figure S2a. With the gradual increase in concentration of TOAB, the oxidation peak current first increased sharply up to 30 $\mu \mathrm{L}$, and then steadily declined. The micellar effect of TOAB might be playing a significant role here, because the peak current changed abruptly around the critical micellar concentration (CMC) of the surfactants. With the aid of information obtained above, $30 \mu \mathrm{l}$ of TOAB was employed for the fabrication of modified electrode in the work.

The influence of immobilization time on the oxidation peak current of $\mathrm{K}_{4} \mathrm{Fe}(\mathrm{CN})_{6}$ is exemplified in Figure S2b. When the immobilization time was raised from 0 to $15 \mathrm{~min}$, the oxidation peak current of $\mathrm{K}_{4} \mathrm{Fe}(\mathrm{CN})_{6}$ also showed great improvement. The increase in immobilization time enhanced the accumulation of $\mathrm{K}_{4} \mathrm{Fe}(\mathrm{CN})_{6}$ at the TOABMCPE surface due to the strong adsorption ability of TAOB. Undoubtedly, the oxidation peak current of $\mathrm{K} 4 \mathrm{Fe}(\mathrm{CN})_{6}$ remarkably increases. However, a very slight increase in the oxidation peak current of $\mathrm{K}_{4} \mathrm{Fe}(\mathrm{CN})_{6}$ was observed when the accumulation time was extended from 15 to $25 \mathrm{~min}$. In order to achieve a quicker analysis with greater sensitivity, $15 \mathrm{~min}$ accumulation time was selected in this work.

\section{Electrochemical impedance spectroscopy}

The Electrochemical impedance spectroscopy was used for the 
Citation: Shankar SS, Shereema RM, Prabhu GRD, Rao TP, Kumara Swamy BE (2015) Electrochemical Detection of Dopamine in Presence of Serotonin and Ascorbic acid at Tetraoctyl ammonium bromide Modified Carbon Paste Electrode: A Voltammetric Study. J Biosens Bioelectron 6: 168. doi:10.4172/2155-6210.1000168

Page 3 of 7

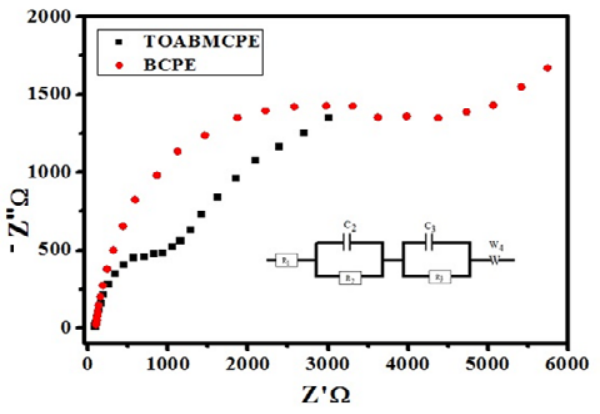

Figure 2: Nyquist diagram of electrochemical impedance spectra of $\mathrm{BCPE}$ and TOABMCPE in PBS at $\mathrm{p}^{\mathrm{H}}$ 7.4. Inset is the equivalent circuit used to analyze the impedance behavior.

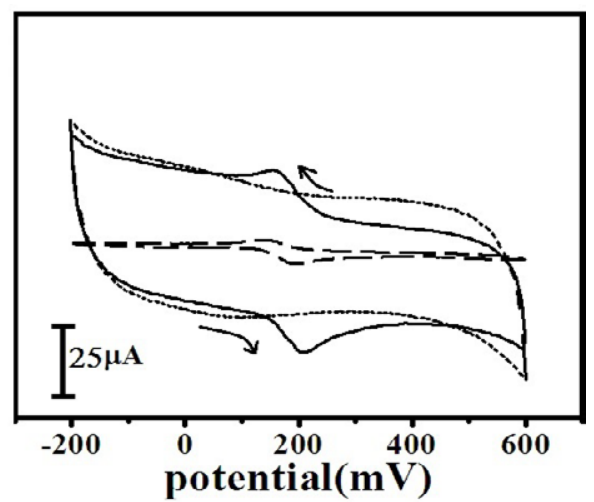

Figure 3: Cyclic voltammograms of bare CPE (dashed line) and TOABMCPE (solid line and dotted line) in $0.1 \mathrm{M}$ phosphate buffer solution of $\mathrm{p}^{\mathrm{H}} 7.4$ (dotted line) and $1 \mu \mathrm{M}$ DA (dashed line and solid line). Scan rate $50 \mathrm{mV} / \mathrm{s}$.

better understanding of electrochemical properties of the electrodesolution interface. Figure 2 showed Nyquist plot of both BCPE and MCPE in PBS at $\mathrm{p}^{\mathrm{H}}$ 7.4. Inset is the equivalent circuit used to analyze the impedance behavior. Large diameter of the semicircle at unmodified electrode with Rct value $3.623 \mathrm{k} \Omega$ indicates the higher electrode resistance towards the electron transfer processes. But after the modification with $\mathrm{TOAB}$, diameter of the semicircle reduces (Rct $0.925 \mathrm{k} \Omega$ ), which implies the lesser resistance by modified electrode towards the charge transfer processes.

\section{Electrocatalytic oxidation of DA at TOABMCPE}

Figure 3 displayed the cyclic voltammograms of $1 \mu \mathrm{M}$ DA in $\mathrm{pH} 7.4$ PBS at BCPE and TOABMCPE. At the BCPE, a pair of redox peak was observed with the oxidation peak potential at $193 \mathrm{mV}$ and the reduction peak potential at $147 \mathrm{mV}$ (dashed line). Whereas the TOABMCPE gave birth to significantly enhanced peak current and a more reversible electron transfer process to DA (solid line) under similar conditions. A well-defined redox wave of DA was observed with respective anodic and cathodic peak potentials at 200 and $152 \mathrm{mV}$. The separation of peak potentials at the TOABMCPE, $\triangle \mathrm{Ep}$ (=Epa-Epc), was $52 \mathrm{mV}$, which was in agreement with the Nernst reversible behavior and approximated the number of electrons involved in the reaction to be two. Intensive increase witnessed in peak current could be owed to the improvement in reversibility of electron transfer process and the larger real surface area of the TOAB film. The repulsion between cationic form of DA and tetraoctylammonium cations adsorbed layer on the surface of modified electrode paved the path to the over potential and increase in the current signals (Scheme S1). To ensure whether the redox peak appeared was for modifier or due to the presence of DA, a blank cyclic voltammogram was recorded only for phosphate buffer (dotted line). Consequently, there were no peaks obtained for the modifier, which suggests the redox peaks obtained were due to the redox behavior of DA. An efficient oxidation reaction toward DA at the TOABMCPE could be inferred through this.

\section{Effect of concentration of dopamine}

The electrocatalytic oxidation of DA was measured by varying its concentration at TOABMCPE. With the increasing concentration of DA from $1 \mu \mathrm{M}$ to $6 \mu \mathrm{M}$, Figure S3 the electrochemical anodic and cathodic peak currents increases with a slight shift of $\mathrm{E}_{\mathrm{pa}}$ and $\mathrm{E}_{\mathrm{pc}}$ towards the positive direction. The graph of anodic peak current vs. concentration of DA displays a linear relationship within the range of $0.10 \mu \mathrm{M}$ to $2 \mu \mathrm{M}$ with the linear regression equation, $\operatorname{Ipa}(\mu \mathrm{A})=0.00313$ $+0.3161(\mathrm{C}) \mathrm{DA} \mu \mathrm{M} / \mathrm{L}$, with a correlation coefficient of 0.997 .

Chronoamperometry was devoted in the determination of lower detection limit, (Figure 4a) showed the chronoamperometric response of TOABMCPE towards DA oxidation in 0.1 M PBS of pH 7.4 at 1200 $\mathrm{mV}$. The resultant calibration graph of current vs. DA concentration (Figure $4 \mathrm{~b}$ ) exhibited a linearity in the lower concentration region $(4 \times$
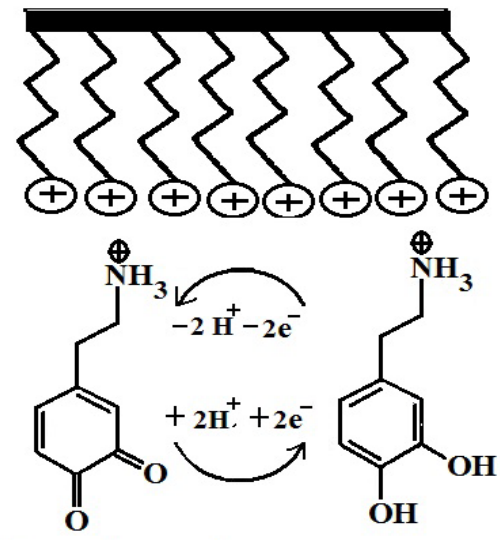

Dopamine-o-quinone Dopamine

Scheme 1: Electrochemical interaction and reduction mechanism of DA at TOABMCPE.

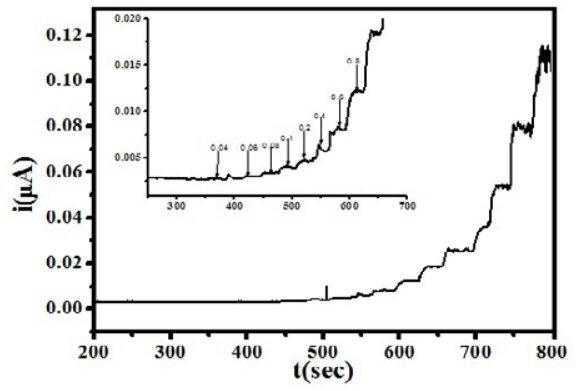

Figure 4a: Chronoamperometric determination of DA with different concentration with a time interval of 30 seconds. Inset shows magnified chronoamperogram from 300 to 700 seconds of time. 
Citation: Shankar SS, Shereema RM, Prabhu GRD, Rao TP, Kumara Swamy BE (2015) Electrochemical Detection of Dopamine in Presence of Serotonin and Ascorbic acid at Tetraoctyl ammonium bromide Modified Carbon Paste Electrode: A Voltammetric Study. J Biosens Bioelectron 6: 168. doi:10.4172/2155-6210.1000168

Page 4 of 7

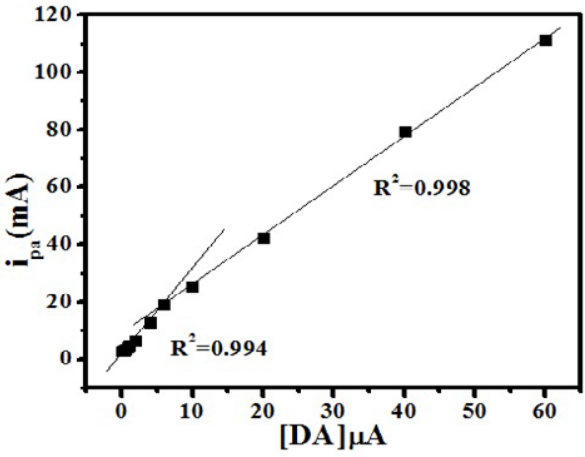

Figure 4b: Graph of Current v/s Concentration of DA

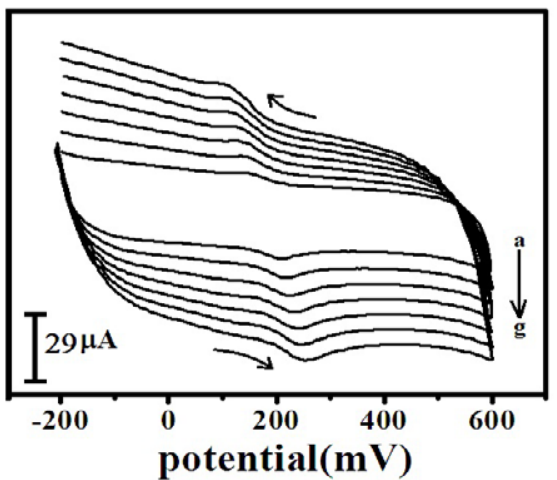

Figure 5: Cyclic voltammograms of $1 \mu \mathrm{M}$ DA at different scan rate (ag; $50,100,150,200,250,300$, and $350 \mathrm{mV} / \mathrm{s}$ in $0.1 \mathrm{M}$ PBS of $\mathrm{p}^{\mathrm{H}} 7.4$

$10^{-8}$ to $\left.6 \times 10^{-6}\right)$ with $\mathrm{R}^{2}=0.994$ and one in higher concentration range $\left(6 \times 10^{-6}\right.$ to $\left.1 \times 10^{-4}\right)$ with $\mathrm{R}^{2}=0.998$. This proves the applicability of the modified electrode both in lower and higher concentration ranges of DA. Through calibration graph, the detection limit determined for DA was $0.019 \mu \mathrm{M}$, based on three times the standard deviation of blank method. The performance of TOABMCPE was compared with the reported surfactant modified electrodes and the results obtained were as denoted in the Table $\mathrm{S} 1$.

\section{Effect of scan rate}

The effect of scan rate on the anodic peak current of $1 \mu \mathrm{M}$ DA at TOABMCPE was studied by cyclic voltammetry (Figure 5). The figure clearly depicts that both the anodic and cathodic peak current increases while the scan rate is increased from 50 to $350 \mathrm{mV}$. The excellent linearity obtained between the scan rate and $\mathrm{I}_{\mathrm{pa}}$ within the range of 50-350 mV/s intimates a surface-controlled process on the modified electrode surface Figure S4. The linear equation was $i_{p}$ $(\mu \mathrm{A})=-0.52+0.548 \mathrm{v}(\mathrm{mV} / \mathrm{s})(\mathrm{r}=0.999)$. This result also denoted the great affinity that DA possessed towards the TAOBMCPE. This suggests the significant role of diffusion in the electrochemical process. Therefore the electrode process assumed to be controlled by diffusion process.

\section{Effect of $\mathrm{pH}$ on the voltammetric response of DA}

The oxidation of $1 \mu \mathrm{M}$ DA was significantly influenced by the $\mathrm{pH}$ of the supporting electrolyte. The variation in peak current and peak potential of DA at TOABMCPE under the influence of change in $\mathrm{p}^{\mathrm{H}}$ was investigated in the $\mathrm{p}^{\mathrm{H}}$ range of 3.4 to 11.4 Figure S5b. As shown in Figure S5a, with a roughly linear increase in $\mathrm{pH}$, the peak potential $\left(\mathrm{E}_{\mathrm{pa}}\right)$ for DA became more negative. The plot of $\mathrm{E}_{\mathrm{pa}}$ versus $\mathrm{p}^{\mathrm{H}}$ was linear with the equation of best fit being: $\mathrm{E}_{\mathrm{pc}}=0.52+0.027 \mathrm{p}^{\mathrm{H}}$ $(\mathrm{R}=0.9986)$. The involvement of equal number of protons and electrons in the electrochemical process could be inferred from this result [32]. Likewise, the effect of $\mathrm{p}^{\mathrm{H}}$ on the peak current is also depicted in Figure S5c. Although, a gradual increase in the peak current of DA with the increase of $\mathrm{p}^{\mathrm{H}}$ from 4.0 to 7.4 was observed with a maximum value at $\mathrm{p}^{\mathrm{H}}$ 7.4, it remarkably decreased with further increase in $\mathrm{p}^{\mathrm{H}}$. Therefore, the phosphate buffer with $\mathrm{p}^{\mathrm{H}} 7.4$ was chosen as the supporting electrolyte for the subsequent experiments.

\section{Electrocatalytic response of AA and 5-HT at TOABMCPE}

The individual voltammetric response of AA and 5-HT at both $\mathrm{BCPE}$ and TOABMCPE are shown in Figures $6 \mathrm{a}$ and $6 \mathrm{~b}$ respectively. The cyclic voltammogram of $0.1 \mathrm{mM}$ AA in $0.1 \mathrm{M}$ phosphate buffer solution at $\mathrm{p}^{\mathrm{H}} 7.4$ showed its anodic peak potential at $229 \mathrm{mV}$ at BCPE (dotted line) with less current response, when compared to the anodic peak potential at TOABMCPE (solid line), under similar conditions, a highly enhanced anodic peak potential was obtained at around -14 $\mathrm{mV}$, which presented a negative shift. This negative shift could be attributed to the presence of cationic monolayer which created the electrostatic attraction of AA. This results in the large shift in the anodic peak potential of AA. The scan rate effect showed that reaction taking place at the electrode surface was diffusion controlled process for AA. The $\mathrm{R}^{2}$ was found to be 0.9989 . Correspondingly, in $\mathrm{p}^{\mathrm{H}} 7.4 \mathrm{PBS}$, the TOABMCPE also possessed strongly electrocatalytic action for 5-HT. Regardless if it is at a BCPE or at the TOABMCPE, only could the oxidation peak be observed in $\mathrm{p}^{\mathrm{H}}$ 7.4 PBS, which confirmed the irreversibility of the electrochemical reaction of 5-HT. At the BCPE the oxidation peak observed for $20 \mu \mathrm{M} 5$-HT was patulous with potential of about $301 \mathrm{mV}$. Meanwhile at the TOABMCPE, the anodic peak potential produced a little negative shift and the shape of the oxidation peak became sharp and symmetrical at the potential of $283 \mathrm{mV}$. It is certain that the TOABMCPE intensively catalyzed the electrochemical oxidation of 5-HT in $\mathrm{p}^{\mathrm{H}} 7.4 \mathrm{PBS}$.

\section{Electrocatalytic oxidation of mixture of AA, DA and 5HT}

AA, 5-HT and DA coexist in the extra-cellular fluid of the central nervous system. The similar oxidation potential of these three at most solid electrodes is a great problem due to their overlapping signal, therefore separate determination of these species is necessitous. To

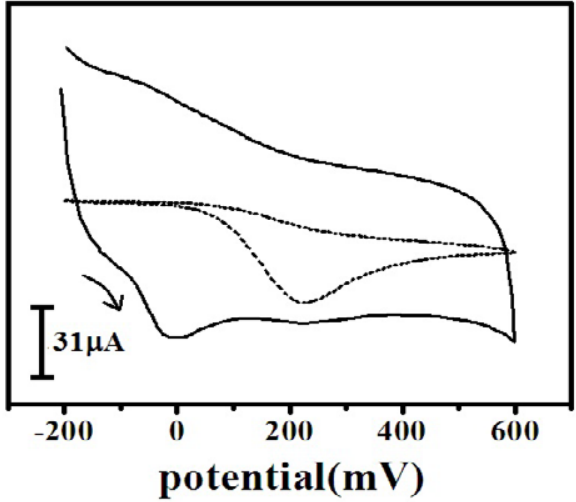

Figure 6a: Cyclic voltammogram of $0.1 \mathrm{mM} \mathrm{AA}$ in $0.1 \mathrm{M}$ PBS of $\mathrm{p}^{\mathrm{H}} 7.4$ at BCPE (dashed line) and TAOBMCPE(solid line). 
Citation: Shankar SS, Shereema RM, Prabhu GRD, Rao TP, Kumara Swamy BE (2015) Electrochemical Detection of Dopamine in Presence of Serotonin and Ascorbic acid at Tetraoctyl ammonium bromide Modified Carbon Paste Electrode: A Voltammetric Study. J Biosens Bioelectron 6: 168. doi:10.4172/2155-6210.1000168

Page 5 of 7

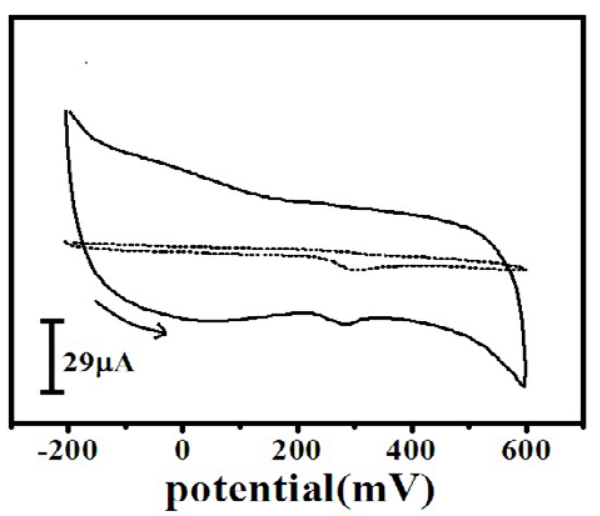

Figure 6b: Cyclic voltammogram of $20 \mu \mathrm{M} 5-\mathrm{HT}$ in $0.1 \mathrm{M}$ PBS of $\mathrm{p}^{\mathrm{H}} 7.4$ at BCPE (dashed line) and TAOBMCPE (solid line).

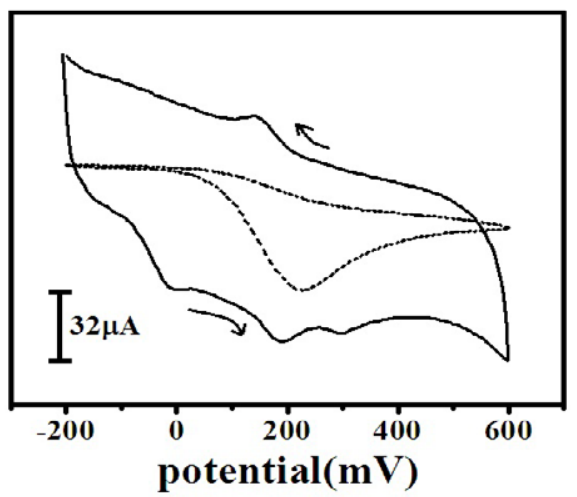

Figure 7a: Simultaneous determination of $0.1 \mathrm{mM} \mathrm{AA}, 20 \mu \mathrm{M} 5-\mathrm{HT}$ and $1 \mu \mathrm{M}$ DA at BCPE (dashed line) and at TOABMCPE (solid line) in $0.1 \mathrm{M}$ PBS of $\mathrm{P}^{\mathrm{H}} 7.4$, scan rate of $50 \mathrm{mV} / \mathrm{s}$

evaluate the sensitivity and selectivity of the present system for the quantification of these molecules, the electrochemical behavior of the mixture of the three at TOABMCPE was examined. Figure 7a showed the CVs of mixture of AA, 5-HT and DA at BCPE and at TOABMCPE in $0.1 \mathrm{M}$ PBS, where the dotted line and solid line correspond to the oxidation of a mixture of $0.1 \mathrm{mM} \mathrm{AA}, 20 \mu \mathrm{M} 5-\mathrm{HT}$ and $1 \mu \mathrm{M}$ DA at TOABMCPE and BCPE, respectively. As envisaged, a poor current response was observed at the $\mathrm{BCPE}$ and three well-defined anodic peaks at the potential of $-6.4 \mathrm{mV}, 190 \mathrm{mV}$ and $297 \mathrm{mV}$ were observed for the oxidation of AA, DA and 5-HT respectively at the TOABMCPE. At the physiological $\mathrm{p}^{\mathrm{H}}$ of 7.4, DA, 5-HT and AA exists in different ionic forms, AA is in anionic form $(\mathrm{pKa}=4.10)$ while $\mathrm{DA}(\mathrm{pKa}=8.87)$ and 5 -HT are in cationic form Captivating the advantage of the opposite micelle effect of DA, 5-HT and AA, a simultaneous quantification of these bioactive compounds was done using TOABMCPE. The difference between the potentials of AA and DA peak was about $196.4 \mathrm{mV}$ and that of DA and 5-HT difference was $107 \mathrm{mV}$, which is sufficient enough for the simultaneous quantification of AA, DA and 5-HT in a mixture. Merely a small oxidation peak shift for DA in the presence of AA indicates the non-interference of these species with each other. The reduction peak of DA in the modified electrode remains unchanged. The above results indicated the exhibition of TOABMCPE with excellent catalytic activity for simultaneous determination of $\mathrm{AA}, \mathrm{DA}$ and $5 \mathrm{HT}$ at reduced and well-separated peak potentials with enhanced sensitivity.
The simultaneous investigation was also done using differential pulse voltammetry (Figure $7 \mathrm{~b}$ ). DPV was employed for its higher current sensitivity with better resolution. The corresponding anodic peak potentials for DA, AA and 5-HT were at 190, -6.4 and $312 \mathrm{mV}$ respectively. The peak to peak separation for DA-AA and 5-HTDA were 196.4 and $122 \mathrm{mV}$ which were more in comparison to the separation achieved by CV.

The oxidation of DA and 5-HT in the presence of increasing concentrations of AA and vice versa were further studied to evaluate the analytical utility of the TOABMCPE. Figure $7 \mathrm{c}$ showed the DPVs recorded for the increasing concentration of DA in the presence of $0.1 \mathrm{mM}$ AA and $20 \mu \mathrm{M} 5-\mathrm{HT}$. The curves (a), (b), (c), (d) and (e) correspond to the presence of $1,2,3,4$ and $5 \mu \mathrm{M}$, respectively. As perceived, an increase in the current response at the DA oxidation peak with the increase in the concentration of DA without any change in the AA and 5-HT peaks could be recognized. Similarly, increase in the concentration of AA in the presence of DA and 5-HT, did not give rise to any significant change in the oxidation current of DA and 5-HT. The curves (a), (b), (c), (d), (e) and (f), in Figure 7d, correspond to the oxidation of $0.1,0.2,0.3,0.4,0.5$ and $0.6 \mathrm{mM}$ AA in the presence of $1 \mu \mathrm{M} \mathrm{DA}$ and $20 \mu \mathrm{M} 5$-HT. An increase in current for AA with the increase in the concentration of AA without any significant change in the oxidation of DA and 5-HT could be clearly distinguished through

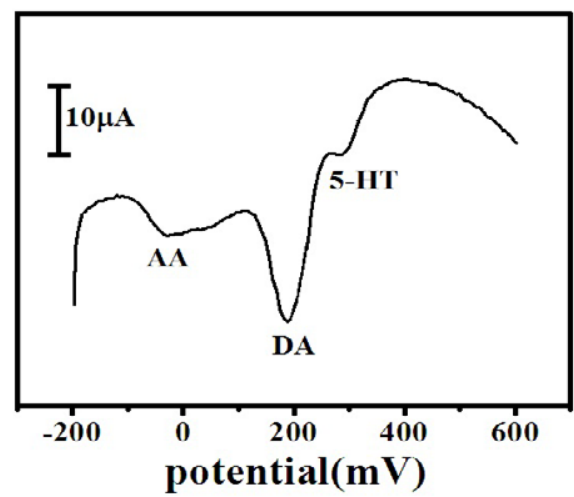

Figure 7b: Simultaneous determination of $0.1 \mathrm{mM} \mathrm{AA}, 20 \mu \mathrm{M} 5-\mathrm{HT}$ and $1 \mu \mathrm{M}$ DA at TOABMCPE in $0.1 \mathrm{M}$ PBS of $\mathrm{pH} 7.4$ by DPV; scan rate 20 $\mathrm{mV} / \mathrm{s}$.

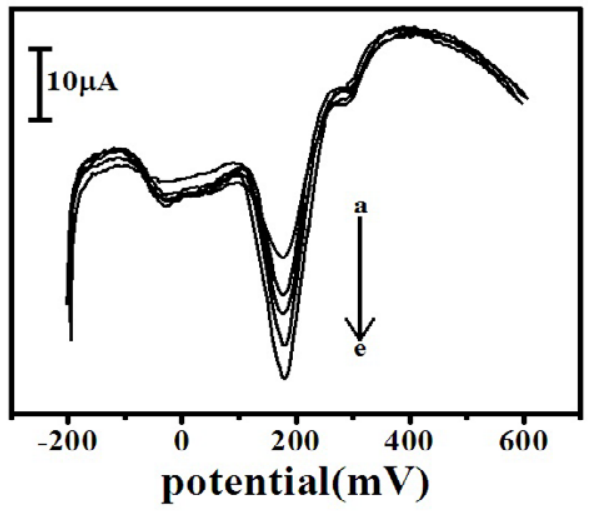

Figure 7c: DPVs of different concentration of DA $(1 \mu \mathrm{M}-5 \mu \mathrm{M})$ in presence of $0.1 \mathrm{mM} \mathrm{AA}$ and $20 \mu \mathrm{M} 5-\mathrm{HT}$ at a scan rate of $20 \mathrm{mV} / \mathrm{s}$. 
Citation: Shankar SS, Shereema RM, Prabhu GRD, Rao TP, Kumara Swamy BE (2015) Electrochemical Detection of Dopamine in Presence of Serotonin and Ascorbic acid at Tetraoctyl ammonium bromide Modified Carbon Paste Electrode: A Voltammetric Study. J Biosens Bioelectron 6: 168. doi:10.4172/2155-6210.1000168

Page 6 of 7

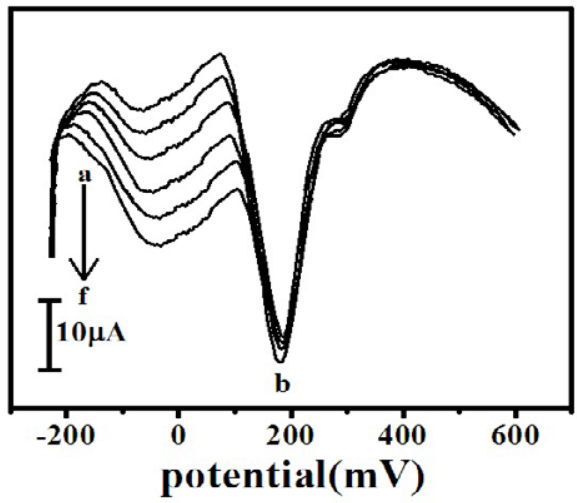

Figure 7d: DPVs of different concentration of AA $(0.1 \mathrm{mM}-0.6 \mathrm{mM})$ in presence of $1 \mu \mathrm{M}$ DA and $20 \mu \mathrm{M} 5-\mathrm{HT}$ at a scan rate of $20 \mathrm{mV} / \mathrm{s}$.

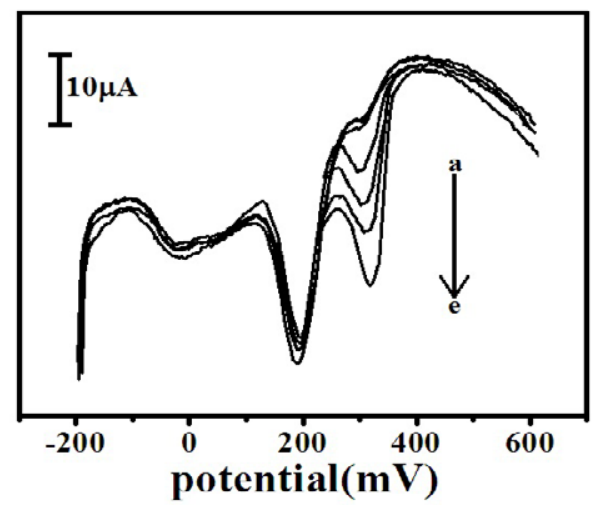

Figure 7e: DPVs of different concentration of 5-HT $(20 \mu \mathrm{M}-60 \mu \mathrm{M})$ in presence of $0.1 \mathrm{mMAA}$ and $1 \mu \mathrm{M}$ DAat a scan rate of $20 \mathrm{mV} / \mathrm{s}$.

this figure. As pictured in Figure 7e, where the concentrations of the AA and DA are constant, the anodic peak current of 5-HT increases linearly with the increase in its concentration from 20 to $60 \mu \mathrm{M}$. It could be inferred from the results that the TOABMCPE could be utilized for the determination of DA in the presence of AA and 5-HT and vice versa. This ability to measure AA, DA and 5-HT in a mixture has significant application in biological and chemical research.

\section{Analytical applications}

Experiments were conducted to evaluate the applicability of the TOABMCPE in the evaluation of DA in the injection sample. Standard addition method was used in the analysis of the injection of DA. With suitable dilution, the DA in their injection sample was determined and the experiment was repeated in five identical setups for all the measurements. Table S2 showed the results of these experiments. The recovery and R.S.D. were acceptable, showing that the proposed methods could be efficiently used for the determination of DA and 5-HT in injections with recovery in the range $98.75-101.25 \%$ and $96.4-$ $104.4 \%$ respectively [33-35].

\section{Stability and reusability of the TOABMCPE}

The relative standard deviation of 6 successive measurements for a DA level of $1 \mu \mathrm{M}$ was $3.0 \%$. When not in use, the TOABMCPE was stored in $0.1 \mathrm{M}$ phosphate buffer of $\mathrm{p}^{\mathrm{H}} 7.4$ [36,37]. After 15 days of storage at room temperature, $96 \%$ of the initial response was observed, indicating the stability of TOABMCPE. The TAOBMCPE could be refreshed by simply immersing in the distilled water at the end of every experiment.

\section{Conclusion}

In this work, a TOABMCPE was fabricated and its characteristics were comprehensively studied. Both CV and DPV techniques were employed in the simultaneous determination of AA, DA and 5- HT in the PBS of $\mathrm{p}^{\mathrm{H}} 7.4$ at the modified electrode. The modified electrode exhibited good stability and sensitivity. Well defined and discrete voltammetric oxidation peaks were observed. The detection limits (LOD) of DA at the TOABMCPE were found to be $0.019 \mu \mathrm{M}$. Moreover, the possible interference of AA and UA in the determination of DA was also studied using the modified electrode and the proposed method has been practically and successfully applied for the determination of DA in dopamine injection samples.

\section{References}

1. Selvaraju T, Ramaraj R (2003) Simultaneous determination of ascorbic acid, dopamine and serotonin at poly (phenosafranine) modified electrode. Electrochem Commun 5: 667-672.

2. Damase-Michel C, Montastruc JL, Tran MA (1995) Effects of dopaminergic drugs on the sympathoadrenal system. Hypertens Res 18 Suppl 1: S119-124.

3. Jose PA, Eisner GM, Felder RA (1998) Renal dopamine receptors in health and hypertension. Pharmacol Ther 80: 149-182.

4. Hussain T, Lokhandwala MF (2003) Renal dopamine receptors and hypertension. Exp Biol Med (Maywood) 228: 134-142.

5. Iván G, Szigeti-Csúcs N, Oláh M, Nagy GM, Góth MI (2005) Treatment of pituitary tumors: dopamine agonists. Endocrine 28: 101-110.

6. Li D, Sham PC, Owen MJL, He H (2006) Meta- analysis shows significant association between dopamine system genes and attention deficit hyper activity disorder (ADHD). Mol Gen 15: 2276-2284.

7. Kienast T, Heinz A (2006) Dopamine and the diseased brain. CNS Neurol Disord Drug Targets 5: 109-131.

8. Khudaish EA, Al Farsi AA (2010) Electrochemical oxidation of dopamine and ascorbic acid at a palladium electrode modified with in situ fabricated iodineadlayer in alkaline solution. Talanta 80: 1919-1925.

9. Wappler F, Fiege M, Schulte am Esch J (2001) Pathophysiological role of the serotonin system in malignant hyperthermia. Br J Anaesth 87: 794-798.

10. Bauer M, Heinz A, Whybrow PC (2002) Thyroid hormones, serotonin and mood: of synergy and significance in the adult brain. Mol Psychiatry 7: 140-156.

11. Goyal RN, Gupta VK, Oyama M, Bachheti N (2007) Gold nanoparticles modified indium tin oxide electrode for the simultaneous determination of dopamine and serotonin: Application in pharmaceutical formulations and biological fluids Talanta 72: 976-983.

12. Mukherjee S, Das SK, Vaidyanathan K, Vasudevan DM (2008) Consequences of alcohol consumption on neurotransmitters -an overview. Curr Neurovasc Res 5: 266-272.

13. Yun HM1, Rhim H (2011) The serotonin-6 receptor as a novel therapeutic target. Exp Neurobiol 20: 159-168.

14. Sun Y, Fei J, Hou J, Zhang Q, Liu Y, Hu B (2009) Simultaneous determination of dopamine and serotonin using a carbon nanotubes-ionic liquid gel modified glassy carbon electrode. Microchim Acta 165: 373-379.

15. Wang Z, Liang Q, Wang Y, Luo G (2003) Carbon nanotube-intercalated graphite electrodes for simultaneous determination of dopamine and serotonin in the presence of ascorbic acid. Journal of Electroanalytical Chemistry 540 129-134.

16. Wu K, Fei J, Hu S (2003) Simultaneous determination of dopamine and serotonin on a glassy carbon electrode coated with a film of carbon nanotubes. Anal Biochem 318: 100-106. 
Citation: Shankar SS, Shereema RM, Prabhu GRD, Rao TP, Kumara Swamy BE (2015) Electrochemical Detection of Dopamine in Presence of Serotonin and Ascorbic acid at Tetraoctyl ammonium bromide Modified Carbon Paste Electrode: A Voltammetric Study. J Biosens Bioelectron 6: 168. doi:10.4172/2155-6210.1000168

17. Jin G, Lin X, Gon J (2004) Novel choline and acetylcholine modified glassy carbon electrodes for simultaneous determination of dopamine, serotonin and ascorbic acid. Journal of Electroanalytical Chemistry 569: 135-142.

18. Kachoosangi R.T, Compton R.G (2007) A simple electroanalytical methodology for the simultaneous determination of dopamine, serotonin and ascorbic acid using an unmodified edge plane pyrolytic graphite electrode. Anal Bioana Chem 387: 2793-2800.

19. Hu S, Wu K, Yi H, Cui D (2002) Voltammetric behavior and determination of estrogens at Nafion-modified glassy carbon electrode in the presence of cetyltrimethylammonium bromide. Analytica Chimica Acta 464: 209-216.

20. Shankar SS, Swamy BEK (2014) Detection of epinephrine in presence of serotonin and the ascorbic acid by TTAB modified carbon paste electrode: A voltammetric study. Int J Electrochem Sci 9: 1321-1339.

21. Hu C, Hu S (2004) Electrochemical characterization of cetyltrimethy ammonium bromide modified carbon paste electrode and the application in the immobilization of DNA. Electrochimica Acta 49: 405-412.

22. Shankar SS, Swamy BEK, Mahanthesha KR, Vishwanatha CC, Kumar M (2013) Simultaneous voltammetric determination of norepinephrine, ascorbic acid and uric acid by TTAB modified carbon paste electrode. Anal Bioanal Electrochem 5: 555-573.

23. He Q, Dang X, Hu C, Hu S (2004) The effect of cetyltrimethyl ammonium bromide on the electrochemical determination of thyroxine. Colloids Surf B Biointerfaces 35: 93-98.

24. Yang $H$, Zheng $X$, Huang W, Wu K (2008) Modification of montmorillonite with cationic surfactant and application in electrochemical determination of 4-chlorophenol. Colloids Surf B Biointerfaces 65: 281-284.

25. Wang XG, Wu QS, Ding YP (2008) Enhancement of surfactants in the electrochemical determination of phenols and the mechanisms research. Colloids and Surfaces A: Physicochem. Eng. Aspects 329: 119-124.

26. Shankar SS, Swamy BEK, Chandrashekar BN (2012) Electrochemical selective determination of dopamine at TX-100 modified carbon paste electrode: A voltammetric study. J molecular liquids 168: 80-86.

27. Chattopadhyay K, Mazumdar S (2000) Direct electrochemistry of heme proteins: effect of electrode surface modification by neutral surfactants. Bioelectrochemistry 53: 17-24.

28. Mimica D, Zagal JH, Bedioui F (2001) Electroreduction of nitrite by hemin myoglobin and hemoglobin in surfactant films. Journal of Electroanalytical Chemistry 497: 106-113.

29. Wang F, Chen X, Xu Y, Hu S, Gao Z (2007) Enhanced electron transfer for hemoglobin entrapped in a cationic gemini surfactant films on electrode and the fabrication of nitric oxide biosensor.Biosens Bioelectron 23: 176-182.

30. Li J, Zhou L, Han X, Liu H (2008) Direct electrochemistry of hemoglobin based on Gemini surfactant protected gold nanoparticles modified glassy carbon electrode. Sensors and Actuators B 135: 322-326.

31. Shankar SS, Swamy BEK, Chandra U, Manjunatha JG, Sherigara BS (2009) Simultaneous determination of dopamine, uric acid and ascorbic acid with CTAB modified carbon paste electrode. Int. J Electrochem Sci 4: 592-601.

32. Mahshid S, Li C, Mahshid SS, Askari M, Dolati A et al. (2011) Sensitive determination of dopamine in the presence of uric acid and ascorbic acid using TiO2 nanotubes modified with Pd, Pt and Au nanoparticles. Analyst 136: 2322

33. Cao X, Luo L, Ding Y, Yu D, Gao Y, et al. (2009) Simultaneous determination of dopamine and uric acid on nafion/sodium dodecylbenzenesulfonate composite film modified glassy carbon electrode. Journal of Applied Electrochemistry 39 1603-1608.

34. Chen SM, Chzo WY (2006) Simultaneous voltammetric detection of dopamine and ascorbic acid using didodecyldimethylammonium bromide (DDAB) filmmodified electrodes. Journal of Electroanalytical Chemistry 587: 226-234.

35. Colin-Orozco E, Avendaño SC, Romero-Romo M, Palomar-Pardavé M Ramírez- Silva MT (2011) Dopamine Electrochemical Determination with Uric and Ascorbic Acids Present in Solution Using a Sodium Dodecyl SulphateModified Carbon Paste Electrode (SDS-CPE) at Physiologic pH. ECS Transactions 36: 373-384.

36. Niranjana E, Kumara Swamy B.E, Raghavendra Naik R., Sherigara BS Jayadevappa $\mathrm{H}$ (2009) Electrochemical investigations of potassium ferricyanide and dopamine by sodium dodecyl sulphate modified carbon paste electrode: A cyclic voltammetric study. Journal of Electroanalytical Chemistry 631: 1-9.

37. Shahrokhian S, Mehrjardi HRZ (2007) Cobalt salophen-modified carbon-paste electrode incorporating a cationic surfactant for simultaneous voltammetric detection of ascorbic acid and dopamine. Sensors and Actuators B 121: 530537. 